\title{
Linpan Community: a Framework of Protection and Development of Rural Landscape in Chengdu Plain
}

\author{
Tao Jiang \\ College of Landscape Architecture \\ Sichuan Agricultural University \\ Chengdu, China
}

\author{
Junzhuo Li \\ College of Landscape Architecture \\ Sichuan Agricultural University \\ Chengdu, China \\ Ahmad Hassan \\ College of Landscape Architecture \\ Sichuan Agricultural University \\ Chengdu, China
}

\author{
Fengjing Zhang \\ College of Landscape Architecture \\ Sichuan Agricultural University \\ Chengdu, China \\ Qibing Chen* \\ College of Landscape Architecture \\ Sichuan Agricultural University \\ Chengdu, China \\ *corresponding author
}

\begin{abstract}
Linpan is a typical settlement in Sichuan, forming a local rural landscape. It is resulted from Dujiangyan irrigation water system that was founded two thousand years ago. During the urbanization construction, the rural landscape in Sichuan is undergoing a complex transition. The survival of Sichuan rural landscape is facing unprecedented challenges such as environmental pollution, farming cultural loss and lack of landscape characteristics. Therefore, a new approach is needed to strike a balance between conservation and development of rural landscape. This paper proposed the concept of Linpan community and discussed its structures, functions and characteristics. Linpan community is a regional society with ecological wisdom of Linpan and convenient life style of community in Chengdu Plain. Linpan Community is a new, compositive settlement. It can provide high-quality life for the local inhabitants. Linpan community has its distinctive leading industries such as agriculture and tourism to bring enough support for the rural economy. It is concluded that, to better protect and utilize Linpan, it is necessary to develop a new rural landscape planning framework for the region that is based on the integration between traditional rural landscape and convenient living condition of community.
\end{abstract}

Keywords-Linpan community; framework; protection development; Chengdu; rural landscape

\section{INTRODUCTION}

With the rapid development of urbanization and the adjustment of the rural industrial structure, the traditional rural settlement landscape pattern is facing severe challenges. The unique production and living patterns and historical and cultural traditions are slowly disappearing. Take Pixian county

*corresponding author, e-mail: cqb@sicau.edu.cn for example, as one part of Chengdu city, Pixian County experienced extraordinary reduction in population in just two years from 11,000 , a density of $25 / \mathrm{km} 2$ in 2004 , to 8,700 , a density of just $20 / \mathrm{km} 2$ at the end of 2006[1]. Population reduction at this astonishing speed threatens the existence of Linpan. Urban expansion resulting in shrinking arable land destabilizes the eco-living settlements formed over thousands of years, thus producing risk of agricultural civilization overturn. Continuous rapid building of new communities that completely abandon the pattern and the concept of traditional villages, assures ecological balance abandonment with fullscale loss of rural landscape identity. In this case, Linpan is in is likely facing the danger of extinction.

Therefore, land use planning to accommodate modern lifestyle while preserving traditional culture in the rural environment is imperative. Landscape planning is essential in providing the balance of a healthy urban environment and a protected rural environment [2]. Qualitative land use planning for sustainable development must be based on natural landscape suitability, demands from residents, ecological characteristics, economics, social and cultural landscape and history, and efficient use of resources as a starting point. Landscape protection must be introduced, thus, as a precondition to reach sustainability for rural landscape as modern development edges in [3].

Considering research and planning design challenges mentioned above, this paper targets production for a new planning and design approach based on the macro-ecological pattern of traditional Linpan and the wisdom of western Sichuan residents in conforming to nature. A designed environment is sought that satisfies local farmers' need while 
protecting the traditional, natural and cultural landscape of Linpan and the production needs of modern life.

Research for the conservation and development of Linpan supports both protection for the current lifestyle and culture pattern in the western Sichuan rural area and the unique environmentally sound landscape. China's new rural construction is a recipient of this research, as well. According to the Chengdu new rural construction layout, around $80 \%$ of farmers will move into new rural communities by the year 2020, while remaining farmers will maintain relatively dispersed living patterns. Land use planning is vital to achieve sustainability as thousands of farmers will seek to settle in new rural communities. Thus, research, as discussed, could help guide about $20 \%$ of the farmers to live in relatively concentrated conditions in a new type of Linpan.

Based on such urgent issues, a conceptual approach is proposed for a new living community. The new "Linpan Community" design will promote construction of proper infrastructure and provide efficient design methodology for a productive living environment in the Chengdu Linpan villages. Rural residential land use intensification and the resulting land use problems mentioned above are the central factors of focus. The conceptual idea of the "Linpan Community" seeks to define qualitative living space for the Chinese rural landscape while providing new ideas for land use and related research, as related to ancestral awareness and the benefits that heritage and ecological wisdom bring.

\section{CONCEPT AND CONNOTATION OF LINPAN COMMUNITY}

Protection needs are indisputable today because of the nonrenewable and irreplaceable attributes of the rural landscape. Rural planning is a successively developing dynamic process and should consider looking to development of the Linpan community for guidance [4]. Linpan now experiences challenges in balancing the needs of humanity and nature. A new type of planning and design, aiming to solve the existing problems, must be presented to spread the inheritance of ecowisdom and to meet farmers' demand while co-existing with the new population demands.

Linpan community is the traditional rural settlement in with comprehensive functions of politics, society, culture, education, etc, providing an inclusive lifestyle for farmers. Linpan community offers satisfaction to the peasants in their daily life. Sustainable development of ecology and economy and regionally inherited cultural characteristics combine providing a qualitative life experience in the new rural community of Linpan. Linpan community can be divided into the settlement level and the unit level. Agriculture and tourism are the leading industries in the Linpan community, which can create employment opportunities for farmers and partially support the rural economy.

\section{FUNCTION AND CHARACTERISTICS}

Linpan community satisfies the needs of the daily production and life of farmers. The traditional landscape reveals human wisdom in the utilization and transformation of nature while farming practices have worked to create the agricultural landscape. China is a great agricultural country with a long history. In spite of thousands of years of evolution from agricultural landscape patterns in Chengdu Plain, the production and the living needs are the controlling factor of agriculture landscape pattern transformation, and the basis of a variety of customs and habits (culture). Linpan community has supported ecological functions to maintain normal human life and the agricultural production. As mentioned before, extended survival of the rural landscape culminates from ecological wisdom and the harmony between man and nature. Chengdu rural landscape for example, benefits from the Dujiangyan water irrigation project. Nature and harmonious ideas then lead the rural landscape to emphasize the relationship between human and nature, and to hold that humans are of the earth and must follow nature's laws.In addition, the Linpan community also promotes landscape aesthetics and tourism. Urban residents wish to experience nature as opposed to the modern city and enjoy the beauty of the rural landscape, providing economic stimuli for the Linpan community. Linpan's combination of farmlands, settlements and waters hold great value visually and socially thereby attracting a tourist trade [5].

Linpan community is the extensions of original Linpan with the original features, elements and forms and new conveniences. Compared with the traditional rural community, Linpan community not only inherited a traditional ecological wisdom, but also solves the problems of the degraded environmental quality, the infrastructure shortage, the poor production and low living standard. Compared with the new rural community, it retains the traditional production, the living space, and rural culture while combining traditional farming with the rural landscape to prevent the loss of tradition features [6].

\section{FramEWORK AND PRACTICAL METHODS}

The purpose of the Linpan community is to protect the traditional landscape resources of Linpan in Chengdu Plain, and to develop into a new type of rural settlement to meet the local farmers' needs. The conceptual framework of the Linpan community can be explored from two levels that can greatly protect and develop Linpan in Chengdu Plain: the level of settlements and the level of unit.

\section{A. Settlement Perspective}

The settlement level planning of the Linpan community contains four components: the natural ecological, the sociocultural, the industrial, and the settlement pattern structure.

1) Natural ecology: Chengdu Plain is located downstream of the Minjiang River. The ecological environment of the upper reaches of the Minjiang River directly determines the ecological security of the Chengdu Plain. The upper Minjiang River is Dujiangyan's ancient cradle of the civilization, the lifeblood and the main resource of water from Sichuan west Linpan. Protection of the upper Minjiang River and the Chengdu Plain is equal to protecting the ecological base of Linpan in the Chengdu Plain. Protective measures can start in three areas; the protection of the forest resources; the 
development and the popularization of clean energy; and the establishment of corresponding mechanism. The concept of ecological barriers comes from the practice of Chinese ecological environment construction. According to the definition of Kai-wen Pan (Chengdu Institute of Biology, Chinese Academy of Sciences), it refers to the key area of a region, and has a good structure of the ecosystem (apparently vegetation ecosystem is the ecological barrier theme and the first element), depending on its self-maintenance and selfcontrol. The ecological environment and the creatures of the system outer or inner have the function of protection and functional biological significance.

2) Society and culture: Needed to protect the traditional Western Sichuan people's lifestyle and customs, and to produce valuable social culture for possible commercialized marketing.Cultural tourism development can expand the traditional culture survival.

3) Industrial: Traditional agriculture is the soul of Linpan in Chengdu Plain, and affects the landscape patterns and forms the western Sichuan traditional agricultural civilization. It is also the main industry of traditional Linpan in Chengdu Plain. Linpan community industry improvement is made on this basis, and the modern agriculture, the tourism, the characteristic industry economy will drive the settlement, meeting the demand of farmers.

4) Settlement structure: In this paper, the supporting infrastructure, the green landscape construction, the drainage, the road landscape, the public space structure ofLinpan community of human settlements were discussed.

Landscape infrastructure include the municipal infrastructure and the public service infrastructure. Traditional landscape infrastructure of Linpan in Chengdu Plain is relatively outdated, and Linpan community infrastructure are based mainly on improved design.

Green construction restores and retrofits the existing green system, combining the new green space to connect the whole ecological forest, the farmland, the traffic corridors, the green barriers, and to build three-dimensional, pluralistic and open green space systems. Linpan community greening can be divided into four kinds of forms, the garden greening, the dotted greening, the belt greening and the piece greening. Garden greening is mainly the unit greening and greening of some public buildings. Dotted greening refers to the isolated tree, the small pieces of green space near the Fengshui trees and public infrastructure. Belt greening is the skeleton of the Linpan community greening system including the road, the river, the ditch greening and the shelter belt. Piece greening refers to the part of the massive ecological forest.

Water system planning is on the basis of the existing agricultural production irrigation system to improve the banks of the rivers, damming, ditches and riverway.Water system planning includes the plane form, the cross section form, the revetment form and the dam of ditches greening. It is needed to transform the plane form of the local section of the main canal, the branch canal and the field ditch, and to avoid the bank line for a single straight line, with rich flow and the appreciation of the landscape enhanced. Road landscape system planning includes improving the road network, strengthening the road greening, and considering the water network system.

Based on the protection of the traditional Linpan in Chengdu Plain public space, Linpan community public space planning is based on the living and production conditions, including the small yards to dry crops, the hydrophilic space, the seniors' activity space, and the children activity space. The yard and square is the open space of the community. The smaller Linpan community is needed to determine the gathering center, and to establish the activity space patterns around the center. The larger Linpan community, the open space should include primary and secondary spaces (concerning the serving radius), and be distributed reasonably. In addition to the natural rivers and streams, the hydrophilic spaces include pond and wells.

\section{B. Unit Perspective}

The landscape units level planning of the Linpan community contains four components: Lin, Shui, Zhai, Tian.

Lin means the garden greening. From the perspective of unit, Lin is mainly composed of a large number of trees, bamboo forest and native shrubs. It surrounds the peripheral Linpan community unit to form an ecological barrier.

Shui means the water landscape in Linpan community, such as ponds, wells, etc. It's preferable to select aquatic plants in landscape configuration to purify the water and to build a micro-ecosystem.

Zhai means the courtyard and the buildings. The practical methods of it are considering the layout according to the terrain situation, and increasing the courtyard greening configuration. Local-style residential characteristics reflect regional characteristics of traditional Linpan in Chengdu Plain, which can be kept and developed. Building structure utilizing bricks or frame constructions with high safety performance are preferred over post and panel structures. The stone, the air bricks, and the concrete can be considered as building materials.

Tian (farmland) is the main physical and biological form unit of rural landscape and an important element embodying the Linpan community landscape. Protection and restoration of farmland landscape should coexist in the planning. Traditional landscape should be combined with modern agricultural production activities, and artificial plant communities combined with wildlife populations so as to achieve biodiversity of the farmland.

The survey indicates that biodiversity of Chengdu Plain farmland mainly concentrates on the edges of the farmland. Undeveloped grasslands and bushes, rich with species, are found on edges of farmland, thus, rich with biodiversity. This paper puts forward three kinds of schemes for the planning of the farmland landscape.

- The dwarf trees and hybridization can be planted at the farmland corners, and be connected through the thickets. 
- The farmland edge can be broadened with grassland. Grass shape can be a narrow strip, and can also be a piece area. Grass not only connects the forest land, the shrub hedgerow and the streams, but also provides wildlife habitat, and reduces agricultural pollutants. Wildflower plantings may also be placed to enhance farmland landscape.

- The farmland edge may be broadened by adding trees and shrubs to create a new structure of large scale landscape.

\section{CONCLUSION}

China's current rapid urbanization development has produced transformation to the rural landscape as a result of productivity. Chinese agricultural landscape is experiencing modifications as its landscape transitions from traditional to modern. A modern mode of industrial production and a new community model have replaced the traditional model, suffering from a drab uniformity. Challenges arise for creating a rural landscape that both protects the original traditional culture resources while adapting to modern production and living conditions and still promotes rural economy development[7].Maintenance of rural landscape sustainability requires development of a new model that is based on traditional ecological wisdom and community planning principles of a regional planning framework.

This paper put forth the concept of the Linpan Community on the basis of long-term research and the exploration of function, characteristics and specific strategies of rural landscape practice. A qualitative rural landscape, in our view, maintains is beauty and stability, provides accessibility, and is compatible and coordinated with the developed landscape space.

Linpan community is a new settlement pattern that combines traditional agriculture landscape wisdom with modern community. Linpan community not only retains the characteristics of the traditional rural landscape, but also honors the heritage and development of traditional farming culture. The work patterns and lifestyle carry traditional culture. Linpan community design satisfies the needs of farmers by providing kinds of functional spaces while improving the farming economy by developing industries (e.g., agriculture) to ensure its sustainable development.

Research indicates two challenges remain to achieve full proven advantage of the Linpan community model. 1. Further studies are needed to define how the Linpan community works in specific operations (e.g., for each landscape elements) for the purposes of protection and development of the rural landscape, and how the policy, the industry, and the farmers demands affect the Linpan community. 2. Additional practice is needed to determine effectiveness of the method of application and evaluation of the Linpan community.

\section{ACKNOWLEDGMENT}

This paper is a partial product of the research project funded by the National Natural Science Foundation of China subsidization project. The project is study on the coupling mechanism of the human physiological and psychological response to the ornamental bamboo and its health function(project code 31570700). This paper is also funded by the Key techniques research and demonstration of Sichuan rare ornamental bamboos cultivation (project code 2012220037) of industry-university-research innovation alliance and the Research and Teaching Enhancement Grant from school of landscape architecture, Sichuan agricultural university.

\section{REFERENCES}

[1] Chen,Q.B., Research on landscape resources protection and development mode of Linpan in Chengdu Plain. China Forestry Press, 2011.

[2] Lewis, P.H., Tomorrow by design--a regional design process for sustainability.John Wiley \& sons,Inc, 1988.

[3] Liu ,B.Y., "Study on Chinese rural landscape",Urban Planning Forum,vol .23,pp66-69,December 2000

[4] Liu, L.M, Zeng, L., Guo, W.H., "Study on rural landscape planning methods of suburbs of Beijing city",Rural ecological environment,vol.17,pp55-58,June 2001.

[5] Fan, J.H., Wei, C., Li, S.Z., "Study on connotation and development of rural landscape",The tropical geography,vol.29,pp285-289,September 2009.

[6] Lin, Q., Wang, X.R., "Regional features and landscape forms",Chinese landscape architecture,vol.21,pp16-24,June 2005.

[7] Yu, K.J., Li, D.H., Han, X.L., “Approach of landscape security patterns - with the case of Magang, Shunde, Guangdong province,"Urban Planning Forum,vol.29,pp:38-45,October 2006. 